\title{
Mechanisms for concurrent low-latitude circulation anomalies responsible for persistent extreme precipitation in the Yangtze River Valley
}

\author{
Yang Chen ${ }^{1,2} \cdot$ Panmao Zhai ${ }^{2}$
}

Received: 13 May 2015 / Accepted: 18 October 2015 / Published online: 2 November 2015

(C) The Author(s) 2015. This article is published with open access at Springerlink.com

\begin{abstract}
Concurrent position shifts of the mid-level western Pacific subtropical high (WPSH) and the upperlevel South Asia high (SAH) are regarded as significant precursors for persistent extreme precipitation events (PEPEs) in the Yangtze River Valley (YRV). By performing composite analyses, accountable vorticity genesis and dissipation are diagnosed based on a potential vorticitydiabatic heating theory. The results indicate that about 1 week preceding precipitation onset, a wave-like pattern of anomalous diabatic heating (Q) initiates its northwestward propagation from equatorial central Pacific. Subsequently, this wave-like pattern induces substantial changes in both horizontal and vertical structure of local Q along the propagating route. Forced negative vorticities in key areas result in the zonal approach between the SAH and the WPSH. During PEPEs, two thermal-induced vertical circulation cells take shape, with common strong ascent centered in the YRV. These anomalous cells are capable of self-maintaining for a few days via positive feedback processes. The WPSH and the SAH are therefore anchored in respective favorable positions for PEPEs. Simultaneously, descending motion of these two cells increases local solar radiation and decreases upward latent heat flux from surface, facilitating warmer underlying surface and swift accumulation of lower-level moisture. Correspondingly, enhanced heating
\end{abstract}

Panmao Zhai

pmzhai@cma.gov.cn

1 Collaborative Innovation Center on Forecast and Evaluation of Meteorological Disasters, Nanjing University of Information Science and Technology, 210044 Nanjing, China

2 State Key Laboratory of Severe Weather, Chinese Academy of Meteorological Sciences, CMA, No. 46, South Ave. Zhong-guan-cun, Haidian, Beijing, China to the north and rapid developing cyclone over warmer sea surface to the south combine to terminate above positive feedback processes. Finally, both the WPSH and the SAH retreat to their normal positions, accompanied by a quick decay of PEPEs.

Keywords Persistent extreme precipitation - Diabatic heating $\cdot$ Precursors $\cdot$ Vorticity budget $\cdot$ Mechanisms

\section{Introduction}

Prolonged weather extremes represent great disastercausing potential owing to their long duration and large spatial coverage (Grumm and Hart 2001). For example, a catastrophic flooding triggered by persistent heavy rainfall hit Pakistan during late July in 2010, threatening 20 million people homeless and causing nearly 3000 deaths only in a few days (Lau and Kim 2012; Galarneau et al. 2012). Predicting such long-lasting extremes with lead time of 1-2 weeks is of great significance for governments in scientific decision-making (Shapiro and Thorpe 2004; Webster et al. 2011). However, it has been reported that many prolonged high-impact weather failed to be detected even by joint efforts of excellent model outputs and experienced forecasters (Root et al. 2007; Dole et al. 2011). Understanding mechanisms responsible for such high-impact events is crucial for model modification and improvement in prediction skills of local forecasters. Substantial attention has been correspondingly paid to related underlying mechanisms for prolonged extremes (e.g. Hong et al. 2011; Galarneau et al. 2012; Chen and Zhai 2014a).

It is generally agreed that extreme phenomena persisting for a few days should receive more emphasis than isolated (1-day) extremes (Zhang et al. 2011). Recently, 
long-lasting precipitation extremes with duration of 3 days or longer have been defined as persistent extreme precipitation events (PEPEs, Chen and Zhai 2013; Ren et al. 2013). Subsequently, particular attention has been paid to PEPEs in the Yangtze River Valley (YRV), where is significantly influenced by Asian monsoon during boreal summer. Pertinent results indicate that various combinations between key systems of certain magnitude make PEPEs extremely dangerous (Müller et al. 2009; Chen and Zhai 2014b). For instance, some typical blocking episodes (Samel 2003; Chen and Zhai 2014a) and recurrent teleconnections (Lau and Weng 2002; Archambault et al. 2008) act to establish quasi-stationary large-scale circulation backgrounds for long persistence of PEPEs. After confirming key circulation systems and their possible configurations, significant precursors with lead time of 1-2 weeks have also been introduced in some recent studies (e.g. Chen and Zhai 2014b, 2015; Ren et al. 2013). Interestingly, in spite of diverse cold air sources from mid-high latitudes in individual cases, one common feature shared by most cases lies in a distinct zonal approach between the western Pacific subtropical high (WPSH) and the South Asia High (SAH) prior to PEPEs, i.e. the WPSH extends westwards and the SAH extends eastwards. Such zonal approach tends to initiate about 1 week prior to PEPEs onset. In nature, PEPEs are intense frontal precipitation processes, which arise from strong ascent of warm/moist air along a quasi-stationary front (Ninomiya and Shibagaki 2007). The WPSH essentially determines anomalously abundant moisture toward the YRV, moisture convergence zone, and low-level jet intensity (Chen et al. 1998; Simmonds et al. 1999; Zhou and Yu 2005; Chen et al. 2007; Chen and Zhai 2014a). Concurrently, the upper-level South Asia High provides conductive divergences for PEPEs (Ren et al. 2007; Jin et al. 2013; Chen and Zhai 2014a, b). Furthermore, an eastward-extended SAH seems imperative to anchor the WPSH to the west of its normal position (Mao and Wu 2006; Chen and Zhai 2015; Jin et al. 2013; Lu and Lin 2009). So, the position anomaly of the SAH is an important factor determining the duration of PEPEs. During PEPEs, the WPSH and the SAH stay in respective favorable positions for extreme precipitation maintenance. After PEPEs, a rapid departure between the WPSH and the SAH is observed. Thus, concurrent anomalies of the WPSH and the SAH can be used as important precursors for predicting PEPEs in the YRV.

The anomalous behavior of the WPSH has been largely attributed to a northwestward propagating convection-circulation pair, which originates from the equatorial centralwestern Pacific (Wang and Xie 1996; Hsu and Weng 2001). Such northwestward-progressive pair features by a quasibiweekly mode (Fukutomi and Yasunari 1999; Kikuchi and Wang 2009; Yang et al. 2010; Cao et al. 2012; Jin et al.
2013). The eastward extension of the SAH seems closely associated with a mid-latitude wave train (Yang et al. 2010; Ren et al. 2015). Coincidently, interaction between diabatic heating and circulations plays significant roles in modulating both the WPSH and the SAH, because varied spatial distribution of the anomalous diabatic heating can induce vorticity variations in both the lower and upper levels (Hong et al. 2015; Ren et al. 2015; Hsu and Weng 2001). Though phenomena concerning the anomalous WPSH and SAH were descriptively presented individually or simultaneously in some previous studies based on specific cases or composited results (Wang et al. 2000; Wu and Liu 2003; Qian et al. 2004; Ren et al. 2007; Mao et al. 2010; Yang et al. 2010; Chen and Zhai 2014b, 2015), detailed mechanisms for the approach, maintenance, and departure of these two dominant systems related to PEPEs have hitherto been rarely systematically reported. This study therefore attempts to discuss the following issues. Firstly, which mechanism leads to the early approach between the WPSH and the SAH prior to PEPEs? Secondly, why these two key systems can persist for several days with little variations in position during PEPEs? Last but not least, how the maintenance of these two systems is terminated, i.e. why they departs from each other swiftly after PEPEs? Additionally, for the WPSH and the SAH, which are both anticyclonic system, their formations and position shifts are closely related to diabatic heating on monthly to seasonal timescales (Liu et al. 2001, 2013; Wu et al. 1999). Thus, on sub-monthly timescales, whether anomalous diabatic heating can explain simultaneous anomalous behaviors of the WPSH and the SAH is also worth exploring.

The remainder of this paper is organized as follows: Sect. 2 introduces the data and method employed in this study. Section 3 describes identification of typical PEPEs associated with simultaneous anomalous WPSH and SAH. Section 4 investigates detailed mechanisms for concurrent anomalous behaviors of the WPSH and the SAH. Finally, Sect. 5 summarizes relevant conclusions and presents some further discussions.

\section{Data and method}

\subsection{Data}

Observational daily precipitation amount at 50 stations in the YRV $\left(28-32^{\circ} \mathrm{N}, 115-123.5^{\circ} \mathrm{E}\right.$, rectangle in Fig. 2) during 1961-2010 are used to build domain-averaged precipitation series. Generally, these stations are evenly distributed across the YRV. This observational dataset is available online http://cdc.cma.gov.cn/home.do.

Daily reanalysis data from 1961 to 2010, including geopotential height $(\mathrm{gpm})$, horizontal wind $(\mathrm{m} / \mathrm{s})$, specific hu 
$(\mathrm{kg} / \mathrm{kg})$, air temperature (K) and relative humidity (\%), are provided by the National Centers for Environmental Prediction and National Center for Atmospheric Research (NCEP/NCAR), at a horizontal resolution of $2.5^{\circ} \times 2.5^{\circ}$ (Kalnay et al. 1996). Such horizontal resolution is high enough for large-scale circulation analyses. Daily outgoing longwave radiation (OLR) from 1979-2010 is obtained from the National Oceanic and Atmospheric Administration (NOAA; Liebmann and Smith 1996). Considering the temporal consistency between the OLR data and atmospheric variables, the composited results, to be documented in the following sections, begin from 1979. To utilize multi-level specific humidity, NCEP/NCAR reanalysis, rather than NCEP-2 reanalysis (the National Centers for Environmental Prediction (NCEP)/Department of Energy (DOE) Reanalysis 2, Kanamitsu et al. 2002) is adopted. To further validate the calculation of apparent heat source, the ERA-interim reanalysis data (Dee et al. 2011) from 1979 to 2010 is also used.

The YRV is located within the famous monsoonal region over East Asia. Under the influence of summer monsoon, the Mei-Yu period typically spans from June to July (Ding 1992; Ding and Chan 2005). Moreover, PEPEs has been reported to occur mainly during the same period in the YRV (Chen and Zhai 2013). June and July are therefore selected as the study period.

\subsection{Methods}

This study is mainly based on a composite analysis, which is a simple and broadly employed yet effective method in identifying typical synoptic to sub-monthly scale circulation patterns and precursors responsible for extreme events (Sisson and Gyakum 2004; Grotjahn and Faure 2008). Considering possible unequal variances of the PEPEs-related fields and climatology (Chen and Zhai 2014a, b), both ordinary Student's $t$ test and Welch's $t$ test (Welch 1947) are conducted to achieve more rigorous statistical significance thresholds. Only the results satisfying both criteria at the 0.05 level at least are deemed statistically significant. Daily climatological mean value and standard deviation $(\sigma)$ of each variable are calculated based on the period of 1971-2000, following the method described by Hart and Grumm (2001). Concretely, for daily climatological mean and standard deviation of precipitation, a 7-day binominal filter is firstly applied (3 days on either side of this day). Then daily climatological mean and standard deviation is calculated based on such smoothed daily precipitation values on this specific day during 50 years. If a 15-day window is adopted for precipitation, consistent cases would be identified. The unequal-weighed binominal filter aims to retain intense precipitation signals and dampen chaotic very-high-frequency signals substantially. For geopotential height field, 21-day running window seems more suitable based on the suggestion of Grumm and Hart (2001). Such $\mathrm{N}$-day sliding window, on one hand, would provide more stable climatological mean and standard deviation compared with only using unsmoothed single-day values; on the other hand, it can also highlight daily variability in contrast to traditional monthly or seasonal means (Junker et al. 2008). Thus, the normalized anomaly of a variable on a specific day is calculated as follows: corresponding climatological daily mean is firstly subtracted; then the value is divided by corresponding climatological daily standard deviation.

Apparent heat source (Q) is calculated following the broadly-performed scheme deduced by Yanai et al. (1973), which takes the form as

$Q=c_{p}\left[\frac{\partial T}{\partial t}+\vec{V} \cdot \nabla_{h} T+\left(\frac{p}{p_{0}}\right)^{R / c_{p}} \omega \frac{\partial \theta}{\partial p}\right]$.

In Eq. (1), $T, c_{p}$, and $R$ denote air temperature, specific heat of dry air at constant pressure, and the gas constant for dry air respectively. In spite of higher resolution of the ERA-interim reanalysis, highly similar results of anomalous fields of Q integrated from surface to $100 \mathrm{hPa}$, can be obtained with these two reanalysis datasets, with slight differences in positions of the maximum and minimum centers (figure not shown). Such trivial differences may be attributed to different horizontal resolution of these two datasets, and they exert little influences on the subsequent analyses. In addition to validating $\mathrm{Q}$ calculation by using different reanalysis data, it is also calculated by another scheme (i.e. Lagrangian perspective) introduced by Mctaggart-Cowan et al. (2007), considering possible influences of computational residuals in Q calculation from daily temporal resolution. Multiple methods are performed to derive the air parcel trajectories, including the Mctaggart-Cowan et al. (2007)'s scheme, Hsu and Weng (2001)'s scheme, and results directly from the HYSPLIT model (Hybrid Single-Particle Lagrangian Integrated Trajectory, from Air Resources Laboratory, NOAA). All the results show similar spatial distribution and propagating route of $\mathrm{Q}$ anomalies. So, it is believed that the Q evaluation from Eq. (1) is reasonably accurate in this study.

The probability density function (PDF), to be presented in Fig. 1, is evaluated with kernel density estimation scheme (Worton 1989), which avoids a pre-assumption of distributional forms of raw data. Both the effective number of degrees of freedom and the significance threshold for the correlation coefficient between filtered series, to be shown in Sect. 5, are evaluated following the method introduced by Pyper and Peterman (1998).

In this study, day $(-d)$ refers to the $d$ th day prior to the onset of PEPEs (start date in Table 1), and day $(d)$ and day $(+d)$ denote the $d$ th day during PEPEs and after the ending of PEPEs (ending date in Table 1), respectively. 
Fig. 1 a Probability density function (PDF) and $\mathbf{b}$ cumulative density function (CDF) of precipitation in the YRV $\left(28-32^{\circ} \mathrm{N}, 115-123.5^{\circ} \mathrm{E}\right)$ during June-July. For the period 19612010, values of 61 days during June to July in every year [totally $3050(50 \times 61)$ days] are binned with a width of 0.1 standard deviation to arrive at the PDF and the CDF. In $\mathbf{b}$, the grey dashed lines correspond to normalized precipitation during the identified PEPEs, and the red dashed lines label their mean value and the corresponding CDF, $\mathbf{c}$ displays the box plot of normalized precipitation anomalies of 186 days accumulated by all the identified cases, in which five horizontal bars indicate the minimum, first quartile, median, third quartile and the maximum respectively. The asterisk denotes the mean value
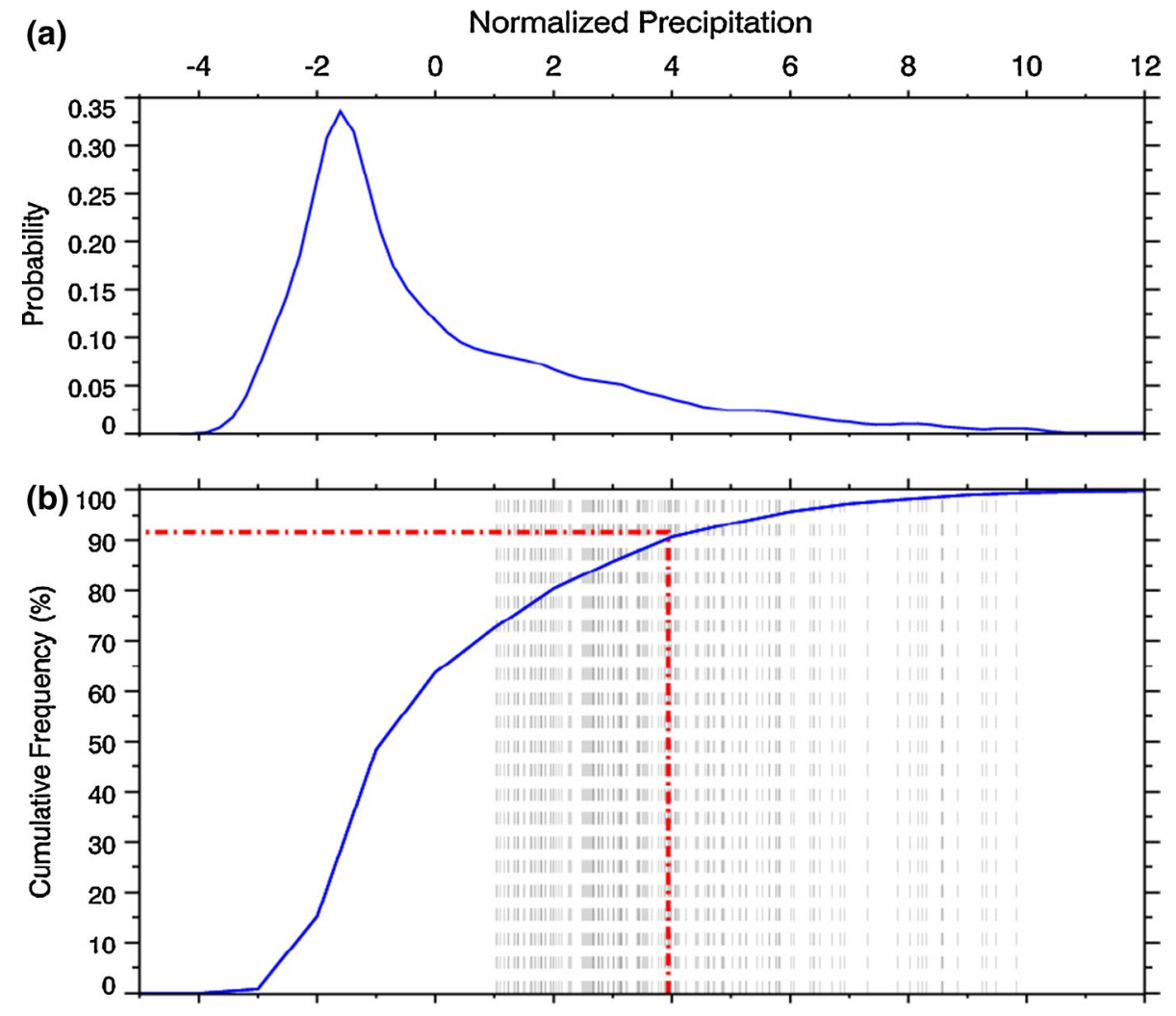

(c)

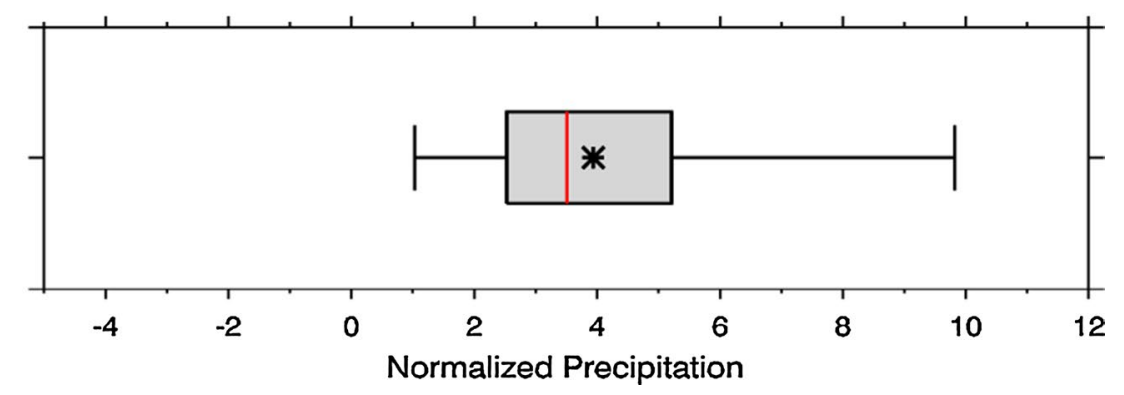

\section{Identification of typical events}

To investigate mechanisms for simultaneous anomalies of the WPSH and the SAH for PEPEs, typical cases need to be identified. A WPSH index (WPSHI) is defined to depict anomalies of the WPSH. The WPSHI is calculated as the normalized anomaly of domain-averaged geopotential height in the region immediately south to the YRV (115$130^{\circ} \mathrm{E}, 15-22.5^{\circ} \mathrm{N}$ ), where is the key area for anomalously abundant moisture transport (Chen and Zhai 2014a, b). Thus, positive anomalies in this area represent westwardextension and enhancement of the WPSH. Also, positive geopotential anomalies in this area can exclude typhooninfluencing PEPEs. For the upper-level SAH, its position shift seems more important to PEPEs than its intensity anomaly (Zhang et al. 2010; Chen and Zhai 2014a, b; Wei et al. 2015). The SAH index (SAHI) is therefore defined as domain-averaged geopotential height in the region of [110$\left.122.5^{\circ} \mathrm{E}, 22.5-30^{\circ} \mathrm{N}\right]$. A SAHI value over $12,520 \mathrm{gpm}$ suggests anomalously eastward shift of the SAH. All the variables and indices firstly go through a five-point binomial filtering procedure to remove very high-frequency signals, which are reckoned as noise for sub-monthly analyses (Ren et al. 2013). The sub-monthly scale refers to the period short than 30 days. Actually, oscillations within these scales are mainly modulated by 10-30-day agents. Particularly, in spite of potential significant low-frequency oscillations in precipitation, typical cases are not selected based on low-frequency agents. Instead, strong signals spanning from a few days to about 2 weeks, i.e. exact sub-monthly scale, are considered based on the original daily records to reflect the real intensity of precipitation. A typical case 
Table 1 The 24 typical persistent extreme precipitation events in the Yangtze River Valley (YRV) during 1961-2010

\begin{tabular}{|c|c|c|c|c|}
\hline Event no. & Year & $\begin{array}{l}\text { Start date } \\
\text { (day-month) }\end{array}$ & $\begin{array}{l}\text { End date } \\
\text { (day-month) }\end{array}$ & $\begin{array}{l}\text { Duration } \\
\text { (days) }\end{array}$ \\
\hline 1 & 1968 & $6 \mathrm{Jul}$ & $10 \mathrm{Jul}$ & 5 \\
\hline 2 & 1969 & $9 \mathrm{Jul}$ & $14 \mathrm{Jul}$ & 6 \\
\hline 3 & 1970 & 23 Jun & 28 Jun & 6 \\
\hline 4 & 1979 & 23 Jun & 27 Jun & 5 \\
\hline 5 & 1979 & $17 \mathrm{Jul}$ & $21 \mathrm{Jul}$ & 5 \\
\hline 6 & 1980 & 7 Jun & 13 Jun & 7 \\
\hline 7 & 1980 & $13 \mathrm{Jul}$ & $17 \mathrm{Jul}$ & 5 \\
\hline 8 & 1982 & 15 Jun & 20 Jun & 6 \\
\hline 9 & 1983 & 25 Jun & $10 \mathrm{Jul}$ & 16 \\
\hline 10 & 1986 & $16 \mathrm{Jul}$ & $20 \mathrm{Jul}$ & 5 \\
\hline 11 & 1987 & $2 \mathrm{Jul}$ & $7 \mathrm{Jul}$ & 6 \\
\hline 12 & 1988 & 17 Jun & 21 Jun & 5 \\
\hline 13 & 1989 & $2 \mathrm{Jul}$ & $6 \mathrm{Jul}$ & 5 \\
\hline 14 & 1991 & $1 \mathrm{Jul}$ & $10 \mathrm{Jul}$ & 10 \\
\hline 15 & 1993 & 14 Jun & 22 Jun & 9 \\
\hline 16 & 1994 & 8 Jun & 14 Jun & 7 \\
\hline 17 & 1995 & 20 Jun & 26 Jun & 7 \\
\hline 18 & 1996 & 29 Jun & $4 \mathrm{Jul}$ & 6 \\
\hline 19 & 1997 & $9 \mathrm{Jul}$ & $14 \mathrm{Jul}$ & 6 \\
\hline 20 & 1998 & 11 Jun & 27 Jun & 17 \\
\hline 21 & 1998 & $17 \mathrm{Jul}$ & $29 \mathrm{Jul}$ & 13 \\
\hline 22 & 2002 & 21 Jun & 28 Jun & 8 \\
\hline 23 & 2003 & $5 \mathrm{Jul}$ & $12 \mathrm{Jul}$ & 8 \\
\hline 24 & 2010 & $4 \mathrm{Jul}$ & $16 \mathrm{Jul}$ & 13 \\
\hline
\end{tabular}

Composite analyses are based on cases after 1979, i.e. No. 4-No. 24

is then retained when satisfying the following criteria simultaneously:

1. daily normalized domain-averaged precipitation of $1.0 \sigma$ (one standard deviation) or greater persists for at least 5 consecutive days;

2. a daily WPSHI of $1.0 \sigma$ or greater persists concurrently;

3. a daily SAHI of 12,520 gpm or greater persists concurrently.

One standard deviation is widely accepted as the threshold to select typical anomalous circulation regimes (Archambault et al. 2008, 2010). The last two criteria aim to identify combined regimes with anomalous WPSH and SAH. It is necessary to adopt relaxed thresholds of both intensity and persistence for combined regimes to ensure an adequate sample size (Archambault et al. 2010). 3-day was used as the typical duration in previous studies (Chen and Zhai 2013; Ren et al. 2013). However, combined with
(2) and (3), the adoption of 3-day would yield large sample size (about 50), among which the break between two events may be less than 1 week. It is not proper to investigate precursors of lead time 1-2 weeks using events with such short temporal gaps. Based on sensitive experiments, 5-day is alternatively adopted as the duration threshold, because it can isolate distinctive events with a proper temporal gap (longer than 15 days, see Table 1). Accordingly, PEPEs in this study refer to the cases composed of at least five consecutive days with daily precipitation greater than 1 $\sigma$ above normal.

There are 24 typical events identified based on above criteria, as listed in Table 1. They account for about $67 \%$ of the total PEPEs during 1961-2010 identified based on the criterion of $1 \sigma$ persisting for at least five consecutive days. Particularly, for the remaining PEPEs, it is possible that though the concurrent anomalies of the WPSH and the SAH can also be detected, but their intensity and position are not as conductive as their counterparts in these 24 events. Further, considering the complexity and diversity of underlying mechanisms for PEPEs in the YRV (Chen and Zhai 2014a, b, 2015), this percentage explicitly highlights the vital significance of the simultaneous anomalous WPSH and SAH in inducing PEPEs in the YRV. Moreover, these 24 cases cover large portion (about $85 \%$ ) of events identified based on either of combined criteria considering $(1)+(2)$ or $(1)+(3)$. This further confirms that the zonal approach between the SAH and the WPSH is a common feature for PEPEs.

The probability density function of June-July precipitation shows a long-tailed skewed distribution (Fig. 1a), with $1 \sigma$ representing approximately the 75th percentile (Fig. 1b). Generally, average intensity of the identified extreme precipitation exceeds the 90th of summertime precipitation in the YRV (red dashed line in Fig. 1b). Specifically, though a relatively smaller threshold is adopted, $75 \%$ of the identified days witnessed extreme precipitation of $2.6 \sigma$ above normal (Fig. 1c). Moreover, days with extreme precipitation of $3.6 \sigma$ above normal and $5.2 \sigma$ above normal account for 50 and $25 \%$ of the total days involved in the identified cases respectively. Such distribution of precipitation intensity clearly indicates the extremity of the identified events, and further verifies the adoption of $1 \sigma$ for extreme precipitation identification. Furthermore, the identification based on $1 \sigma$ may imply 40-50 $\mathrm{mm} \mathrm{day}^{-1}$ or greater in the precipitation center at an individual station level (see Fig. 2f-h). Though 40-50 $\mathrm{mm} \mathrm{day}^{-1}$ seems not very extreme in the YRV during monsoonal season, the accumulated amount above $200 \mathrm{~mm}$, owing to the long duration, will highly likely trigger a severe flood in a large area within just a few days. Figure $2 \mathrm{f}-\mathrm{h}$ also illustrates that the identified events bear 
Fig. 2 Solid contours (588dagpm) and dashed contours (1252-dagpm) portray the activities of the WPSH at $500 \mathrm{hPa}$ and the $\mathrm{SAH}$ at $200 \mathrm{hPa}$, respectively. Daily precipitation amount above $10 \mathrm{~mm} /$ day deviation are shaded with interval of $5 \mathrm{~mm} /$ day. The red rectangle labels the region of the Yangtze River Valley. The number- $\mathrm{d}$ at the upper-left corner in each panel refers to the $d$ th day prior $(-)$ to, during (day), and after (+) the PEPEs onset
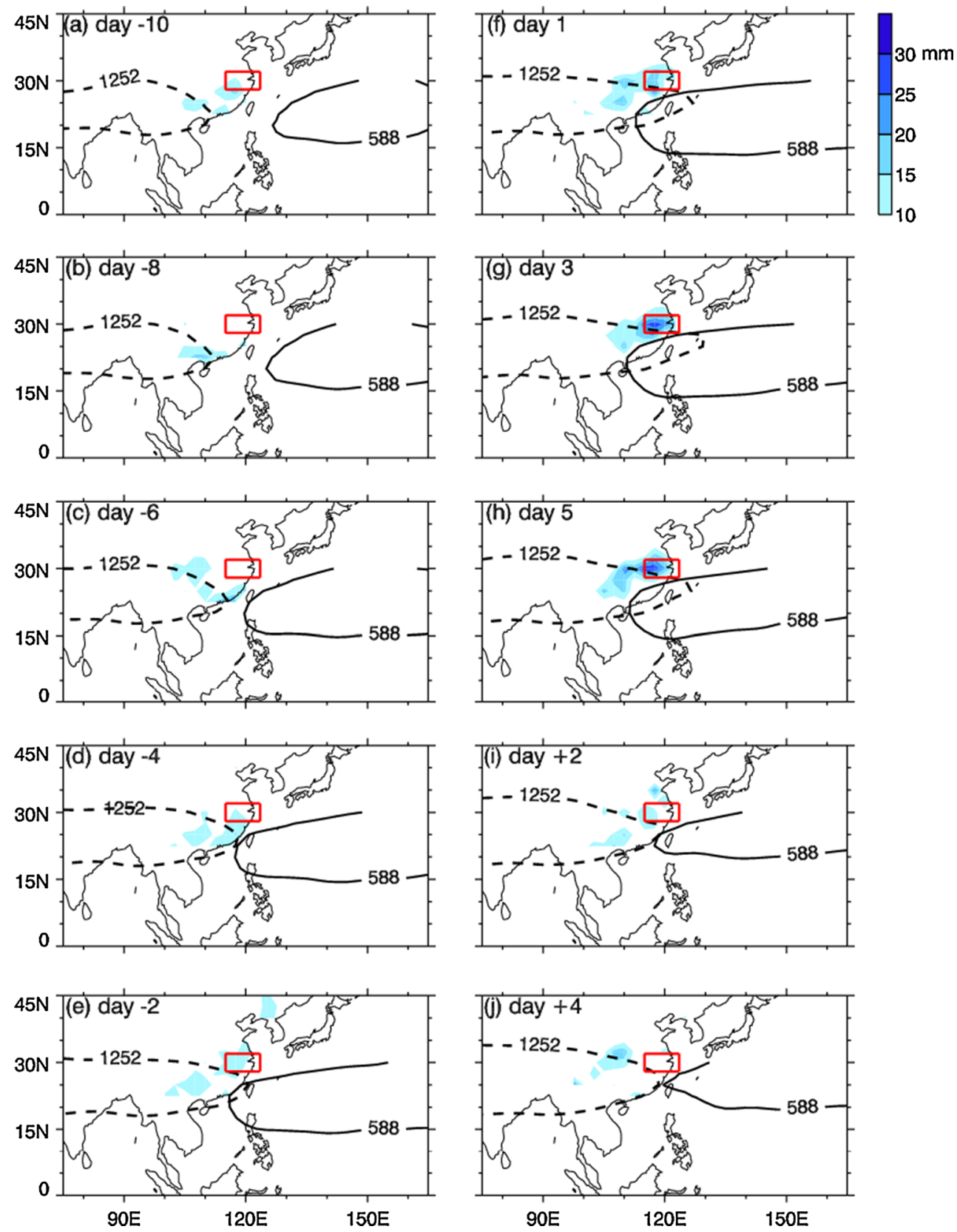

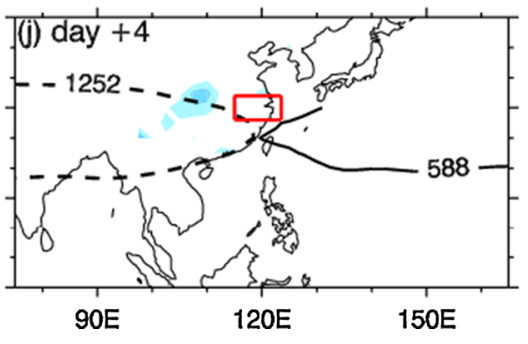

the property of frontal processes affecting a broad spatial extent, rather than local convective activity restricted within a small area.

\section{Anomalous apparent heat source and large-scale circulations}

The period from day 1 to day 5 portrays the persistence of extreme precipitation. In addition to composites for the 21 cases after 1979, composites for subsets grouped arbitrarily (i.e., in chronological order; not shown) are also performed. The similarity between the results based on different subsets implies a sufficient insensitiveness of composites to the inclusion or exclusion of specific events.

\subsection{Circulation pattern evolution}

Gradual westward extension of the WPSH (indicated by 588 dagpm-contour) can be traced back to day -8 (Fig. 2). From day -6 onward, the westward extension further accelerates. By day -2 , the west boundary of the WPSH has reached $120^{\circ} \mathrm{E}$. During PEPEs, the WPSH is anchored in the immediate south of the YRV. After PEPEs, the WPSH retreats eastward rapidly, and it retrogrades to the east of $125^{\circ} \mathrm{E}$ after day +6 . During westward migration 
of the WPSH, the South Asia High at $200 \mathrm{hPa}$ (indicated by 1252 dagpm-contour) stretches eastward concurrently, particularly from day -4 onward. By day -2 , the east boundary of the SAH has encountered the west boundary of the WPSH. During PEPEs, an overlapping between the SAH and the WPSH maintains in the coastal region over South China As the rapid decay of extreme precipitation $($ day +2$)$, the SAH and the WPSH depart from each other toward the opposite directions. Apparently, the zonal approach initiates about 1 week prior to PEPEs onset.

\subsection{Apparent heat source evolution and its influences on the WPSH and the SAH}

Summertime climatological configuration between the SAH and the WPSH is presented in Fig. 3. During JuneJuly, the WPSH typically stays to the east of $130^{\circ} \mathrm{E}$, and the SAH stays around $110^{\circ}$ E. Such configuration highly resembles the pattern from day -10 to day -8 in Fig. 2. It is a long distance of 25 longitudes between these two key systems. A southeast-northwest oriented belt of large positive apparent heat source is observed from equatorial central Pacific to southern part of the Tibetan Plateau.

Prior to PEPEs onset, a wave-like pattern of anomalous Q (shadings) can be identified up to day -8 (Fig. 4). A similar wave-like pattern with reverse signs can also be detected in the anomalous field of OLR (not shown). The correspondence between positive (negative) Q anomaly and negative (positive) OLR anomaly indicates convective nature of this wave-like pattern. During the early period (day -8 to day -6 ), this wave-like pattern of anomalous $\mathrm{Q}$ mainly propagates westward, with small variations in magnitude. Subsequently, the wave-like pattern shifts northward gradually and strengthens saliently (day -4 to day -1). During PEPEs, a well-organized wave-like pattern is anchored over East Asia and persists for several days (day 1-5). At this phase, this anomalous wave-like pattern consists of heating from the YRV eastward to Japan and regions southeast of the Philippines, and cooling in the regions both to the south and north of the YRV. During the decay period (day +2 to day +6 ), the wave-like pattern of anomalous $\mathrm{Q}$ restarts its northwest propagation. The strong heating in the YRV during PEPEs vanishes. Alternatively, anomalous heating appears to the immediate north of the YRV and the northern Philippines, where experienced anomalous cooling during PEPEs. It is widely agreed that a moist Rossby wave in the lower troposphere may account for the northwestward propagation of the convective heating in the western North Pacific (Wang and Xie 1996; Xie and Wang 1996; Kemball-Cook and Wang 2001; Hsu and Weng 2001). Moisture flux vorticity at $850-\mathrm{hPa}$ (contours) is used to delineate the low-level moist Rossby wave. Obviously, prior to the onset, the moist cyclones/anticyclones are located to the north/northwest of the diabatic heating anomalies, signaling moisture convergences/divergences lead the diabatic heating/cooling spatially. Based on the theory of Wang and Xie (1996), such leading moisture convergences/divergences can enhance/reduce the atmospheric instability and local ascent/descent, further guiding the northwest propagation of the coupled low-level circulations and diabatic heating/cooling. During PEPEs, instead of a spatially leading relationship, the vorticities and diabatic heating/cooling nearly vary in phase. This phenomenon implies that some local influences slow down the northwest progression. After PEPEs, the vorticity leads the diabatic heating again, corresponding to the re-initiation of the northwest propagation. Further detailed mechanisms of northwest propagation are beyond the main focus of this
Fig. 3 Climatology of integrated apparent heat source (Unit: $\mathrm{W} \mathrm{m}^{-2}$ ) during June-July (shadings). Solid and dashed contours denote climatology of the WPSH and the SAH during June (black), July (red), and June-July (blue), respectively

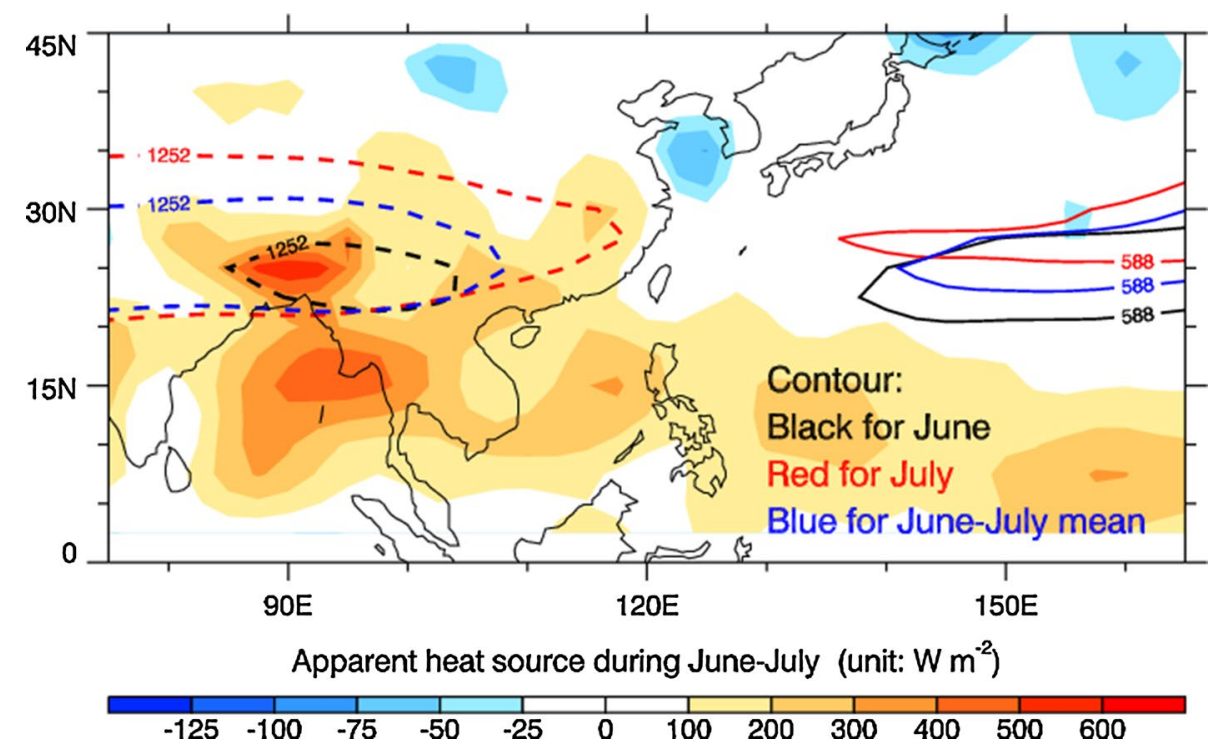



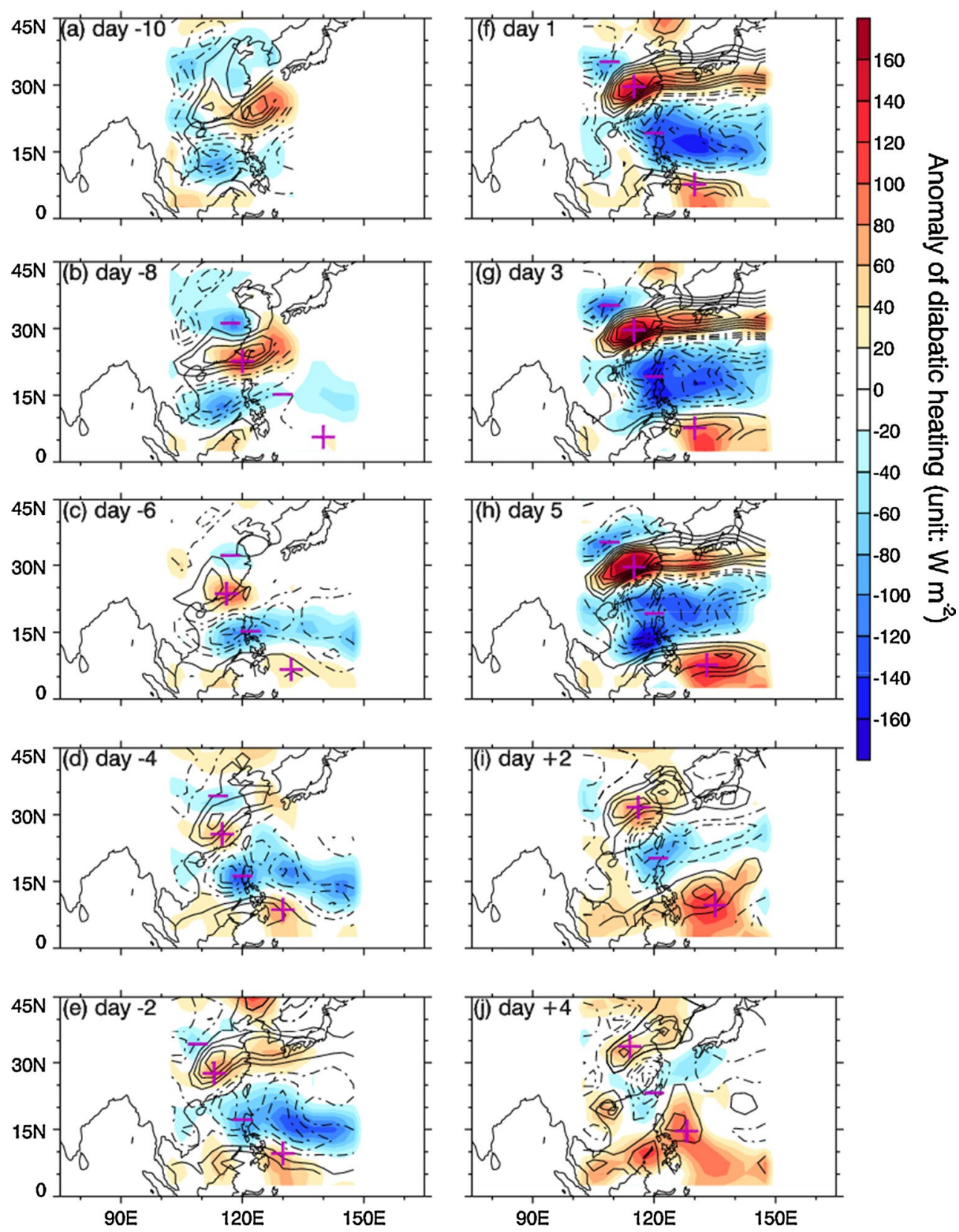

Fig. 4 Composited anomalies of the integrated apparent heat source $(Q$, shadings) and the vorticity of moisture flux at $850 \mathrm{hPa}$ (contours, dashed for negative and solid for positive, from $-12 \times 10^{-8}$ to $12 \times 10^{-8} \mathrm{~s}^{-1}$ with interval of $2 \times 10^{-8} \mathrm{~s}^{-1}$ and contour- 0 is

neglected). The purple symbols '+' and '-' generally delineate the positions of diabatic heating belts. Only the anomalies that are at least significant at the $5 \%$ level are shown. The number above each panel represents the same meaning of that in Fig. 2

study, and they are concretely illustrated by Wang and Xie (1996).

Interestingly, such wave-like pattern of anomalous $\mathrm{Q}$ seems coincidently to fill the zonal gap between the normal WPSH and SAH as revealed in Fig. 3. It is therefore rational to hypothesize that such wave-like pattern of anomalous Q may account for simultaneous anomalies of the WPSH and the SAH. Both the WPSH and the SAH are anticyclonic systems, thus genesis and dissipation of

negative vorticity essentially determine their anomalous behaviors. Following the Ertel potential vorticity equation (Ertel 1942; Hoskins et al. 1985), some theoretical studies deduced the vertical vorticity equation with external forcing as (Wu and Liu 1998; Wu et al. 1999; Liu et al. 1999, 2001, 2004)

$$
\frac{\partial \xi}{\partial t}=-\underset{\mathrm{a}}{\vec{V}} \nabla \underset{\mathrm{b}}{\beta v}-(f+\underset{\mathrm{c}}{\xi}) \nabla \vec{V}+\frac{f+\xi}{\theta_{z_{\mathrm{d}}}} \frac{\partial Q}{\partial z}+\underset{\mathrm{e}}{S} ;
$$



anomalies at $200 \mathrm{hPa}$ (vectors), anomalous negative vorticities genesis forced by item $d$ in Eq. (2), $\frac{f+\xi}{\theta_{z}} \frac{\partial Q}{\partial z}$ (blue contours from $-2 \times 10^{-11}$ to $-10 \times 10^{-11} \mathrm{~s}^{-2}$ with interval of $-2 \times 10^{-11} \mathrm{~s}^{-2}$ ), and anomalous negative vorticities genesis forced by item $\mathrm{S}$ in Eq. (3) (red contours from $-0.5 \times 10^{-11}$ to $-0.5 \times 10^{-11} \mathrm{~s}^{-2}$ ). The wind anomalies that are significant at the 0.05 level are highlighted by black vectors. The key region-A for the eastward extension of the South Asia High is marked by green rectangle. The number above each panel represents the same meaning of that in Fig. 2
Fig. 5 Composited wind $-3 \times 10^{-11} \mathrm{~s}^{-2}$ with interval of
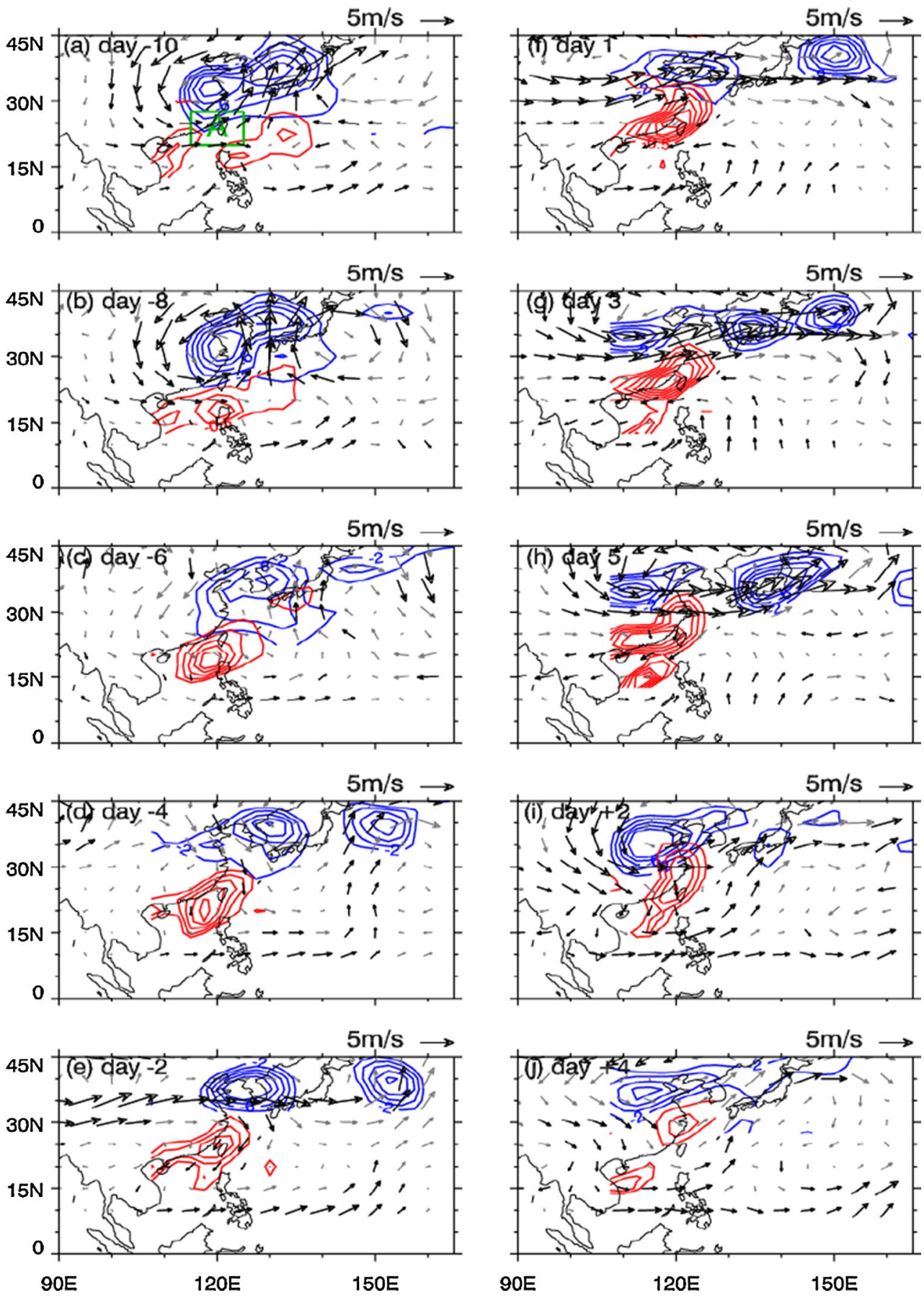

$S=-\frac{1}{\theta_{z}} \frac{\partial v}{\partial z} \frac{\partial Q}{\partial x}+\frac{1}{\theta_{z}} \frac{\partial u}{\partial z} \frac{\partial Q}{\partial y}$.

$\xi$ on the left side of Eq. (2) represents relative vertical vorticity. On the right side of Eq. (2), five items represent the advection of vorticity, $\beta$ effect, divergence (convergence) effect, vertical and horizontal gradients of diabatic heating, respectively. In Eq. (3), $\theta_{z}$ denotes the static stability. The first three items in Eq. (2) are atmospheric internal processes, and the last two items represent external forcings.
Within the diabatic heating region, the vertical heating gradient $\left(\frac{\partial Q}{\partial z}\right)$ largely determines the forcings, whereas around the border area the horizontal heating gradient (i.e., S) also plays an important role (Wu and Liu 1998; Liu et al. 2001). Two key regions, southeast of the SAH at $200 \mathrm{hPa}$ (region-A labeled in Fig. 5a) and southwest of the WPSH at $500 \mathrm{hPa}$ (region-B labeled in Fig. 7a), are selected to investigate the responsible vorticity genesis and dissipation. Firstly, it is necessary to confirm the balance of vorticity budget via Eq. (2). Within both region $\mathrm{A}$ and $\mathrm{B}$, the 
Fig. 6 Temporal evolution of anomalies of five items in Eq. (2) at $200 \mathrm{hPa}$, including vorticity advection- $a, \beta$ effect- $b$, divergence/convergence effect$c$, vertical gradient of $Q-d$, and horizontal gradient of $\mathrm{Q}-e$. Sum of these five items is presented by purple bold line in $\mathbf{a}$. All the items are averaged within the region- $A$ marked in Fig. 5. The numbers labeled along the $x$ axis represent the same meaning of that in Fig. 2
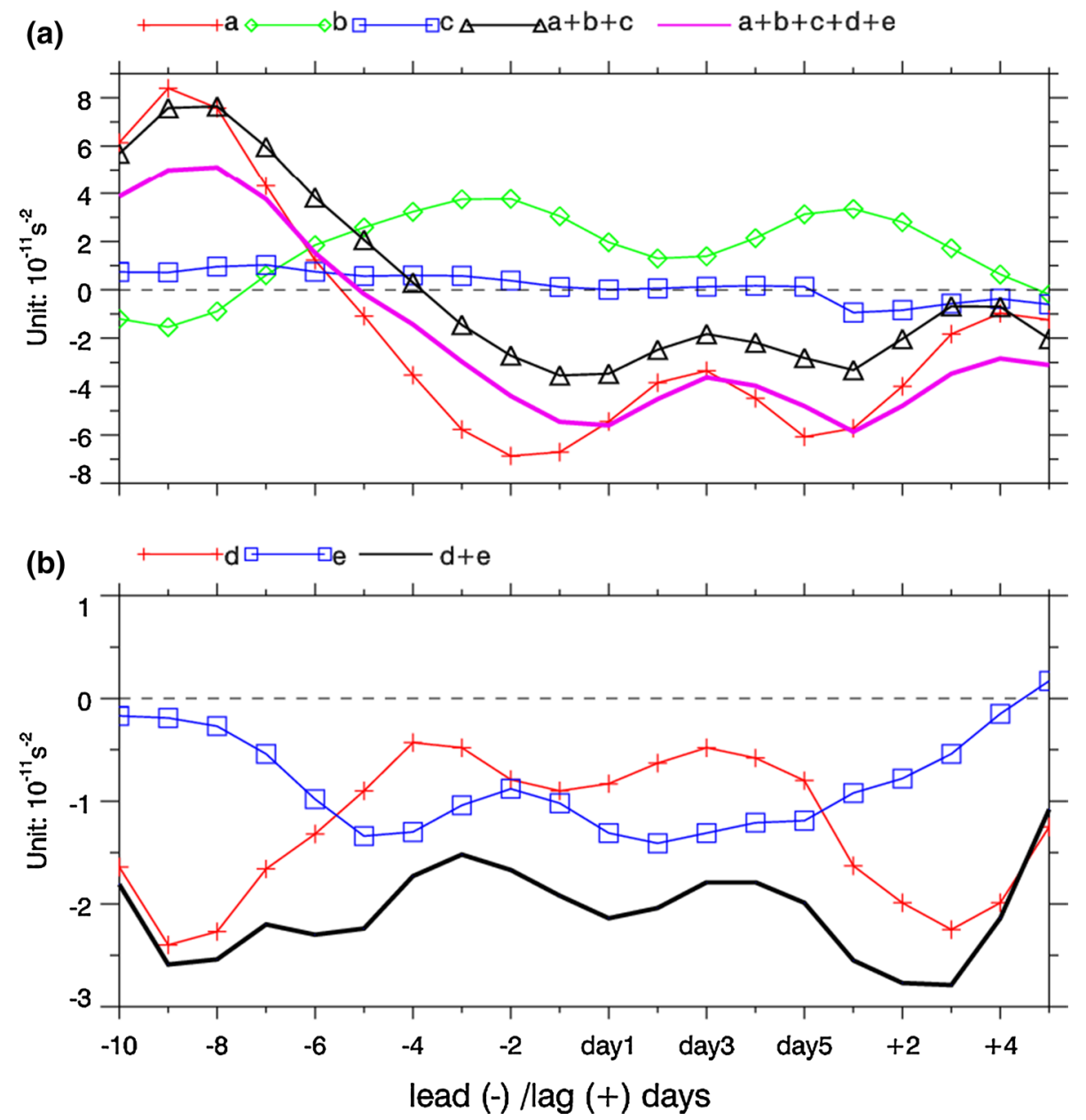

difference between the direct tendency $\frac{\partial \xi}{\partial t}$ and the results from the sum of a-e is one order of magnitude small than the tendency itself. This means the following analyses are based on the balanced framework of vorticity budget.

In the upper troposphere, from day -10 to day -6 , a pre-existing anomalous cyclone (Fig. 5) advects strong positive vorticity toward southeastern China (Fig. 6a, item a), inhibiting the SAH from extending eastward. Strong negative vorticity genesis gradually disperse the anomalous cyclone, leading to a rapid decay of positive vorticity advection (Fig. 6a, item a). The SAH correspondingly initiates its eastward extension as indicated by the appearance of northerly anomalies over coastal region (from day -4 onward). During early periods (day -10 to day -5 ), when the wavelike pattern of anomalous Q still remains relatively south, greatly enhanced diabatic heating is restricted in region-A. Considering the maximum heating typically in $500-400 \mathrm{hPa}$ in region-A (Fig. 7a, black line), such enhanced heating with maximum value in the lower-mid troposphere (Fig. 7a, red line) triggers a sharper decrease of $\mathrm{Q}$ with height in the upper troposphere. This sharper decrease renders a larger absolute value of $\frac{\partial Q}{\partial z}$ at the upper troposphere, which further forces an anomalous negative vorticity according to Eq. (2). Physically, a sharper decrease of Q with height facilitates a higher-elevated upper isobaric surface. Enhanced divergent winds emanate from local stronger positive isallobaric region. The exertion of the Coriolis force turns these accelerated divergent winds into anticyclonic shears. As northward migration of the wave-like pattern of anomalous Q (from day -4 onward, Fig. 4), region-A witnesses an enhanced meridional gradient of $\mathrm{Q}$ composed of a negative $\mathrm{Q}$ anomaly in the south and a positive $\mathrm{Q}$ anomaly in the north $\left(\frac{\partial Q}{\partial y}>0\right)$. Combined with local easterly shear $\left(\frac{\partial u}{\partial z}<0\right)$, the second item in $\mathrm{S}$ also provides a negative vorticity source according to Eqs. $(2,3)$ (Fig. 5, red contours). Apparently, this negative vorticity source from $\mathrm{S}$ shows northwest propagating feature along the propagating route of $\mathrm{Q}$. During this period, the meridional contrast of $\mathrm{Q}$ plays a more important role than the vertical counterpart (Fig. 6b). The first item in $\mathrm{S}$ can be neglected since the zonal gradient of $\mathrm{Q}$ is quite small. Physically, such enhanced meridional contrast of $\mathrm{Q}$ favors the acceleration/slowdown of local easterlies/westerlies, which forces anticyclonic shears to the north. It seems plausible that the genesis of negative vorticiy is largely contributed by 
Fig. 7 Domain-averaged vertical distribution of heating rate $\left(\mathrm{K} \mathrm{day}^{-1}\right)$ in region- $A(\mathbf{a})$, and in region- $B$ (b)

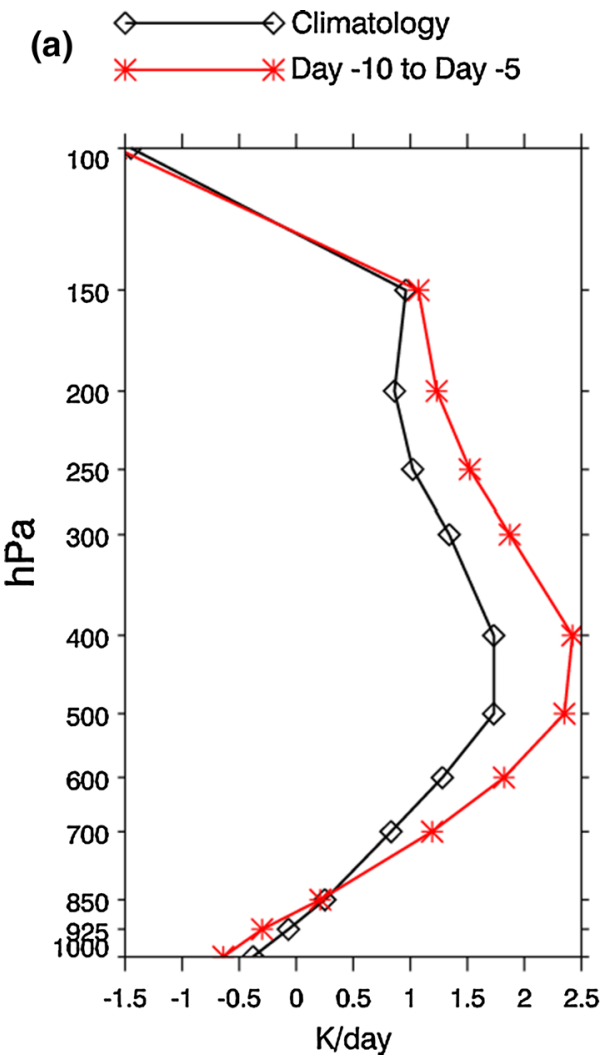

vorticity advection from day -6 onward (Fig. 6a). Of note is that the eastward-extended $\mathrm{SAH}$ also advects negative vorticity toward region-A. This means that strong negative vorticity may largely be the consequence of the eastward extension of the $\mathrm{SAH}$, rather than the causation. The positive $\beta$ effect may also be determined by northerlies induced by eastward-extended SAH. Contributions from divergence (convergence) effect can be neglected. After PEPEs, as the wave like pattern of $\mathrm{Q}$ restarts northwest propagation, the negative vorticity genesis weakens swiftly. A cyclone shear establishes over coastal region again. Hence, the SAH retrogrades eastward.

At $500 \mathrm{hPa}$, in region-B (Fig. 8), a pre-existing negative $\mathrm{Q}$ anomaly is maintained by the westward-migrated cooling at lower latitudes. As northwest propagation of the wave-like pattern, the cooling expands northwestward. Actually, the long-lived cooling in region-B reduces the vertical contrast of $\mathrm{Q}$ around the $500 \mathrm{hPa}$, leading to an evident decrease of the positive value of $\frac{\partial Q}{\partial z}$ around $500 \mathrm{hPa}$ (Fig. 7b, red line). A negative vorticity is accordingly forced (Figs. 8, 9b, item d). From day -3 onward, further westward extension of diabatic cooling leads to a decreased $\frac{\partial Q}{\partial z}$ of larger magnitude, which results in further developed negative vorticity (Fig. 7b, blue line; Fig. 9b, item d). Judging from Fig. 8, changes in vertical structure of $\mathrm{Q}$ mainly account for the westward extension of the WSPH, while sharp horizontal contrast of Q favors its northward expansion, especially after day -4 . Actually, the anomalous diabatic cooling shrinks the air column, with sinking isobaric surfaces in the upper levels and rising ones in the lower levels. The upward extending isobaric surface in the lower levels also facilitates the formation of the anomalous anticyclone via geostrophic adaptation process. Of particular note is that the $\beta$ effect seems to play an important role in triggering negative vorticity. During this period, the WPSH has already reached $120^{\circ} \mathrm{E}$, with southerly anomaly to its west boundary. The negative value of $\beta$ effect may therefore be the consequence of the westward extension of WPSH, rather than the causation. Also, the divergence effect can be neglected.

After PEPEs, as the wave-like pattern of anomalous $Q$ is re-organized, the negative vorticities forced by anomalous diabatic heating in both $\mathrm{A}$ and $\mathrm{B}$ vanish, and they come back to nearly zero after day +6 .

\subsection{Mechanisms for maintenance}

Near the onset of PEPEs (Fig. 10a), as the WPSH encounters the SAH, enhanced low-level southwesterlies advect abundant moisture toward the Yangtze River. Thus moisture accumulates as indicated by the upward-stretching moist 
Fig. 8 Similar to Fig. 5, but for $500 \mathrm{hPa}$. Blue contours $-5 \times 10^{-11} \mathrm{~s}^{-2}$ with interval of $-1 \times 10^{-11} \mathrm{~s}^{-2}$, and red contours are from $-0.5 \times 10^{-11}$ to $-3 \times 10^{-11} \mathrm{~s}^{-2}$ with interval of $-0.5 \times 10^{-11} \mathrm{~s}^{-2}$. The key region- $B$ for the westward extension of the western Pacific subtropical high is marked by green rectangle. The number above each panel represents the same meaning of that in Fig. 2 are from $-1 \times 10^{-11}$ to
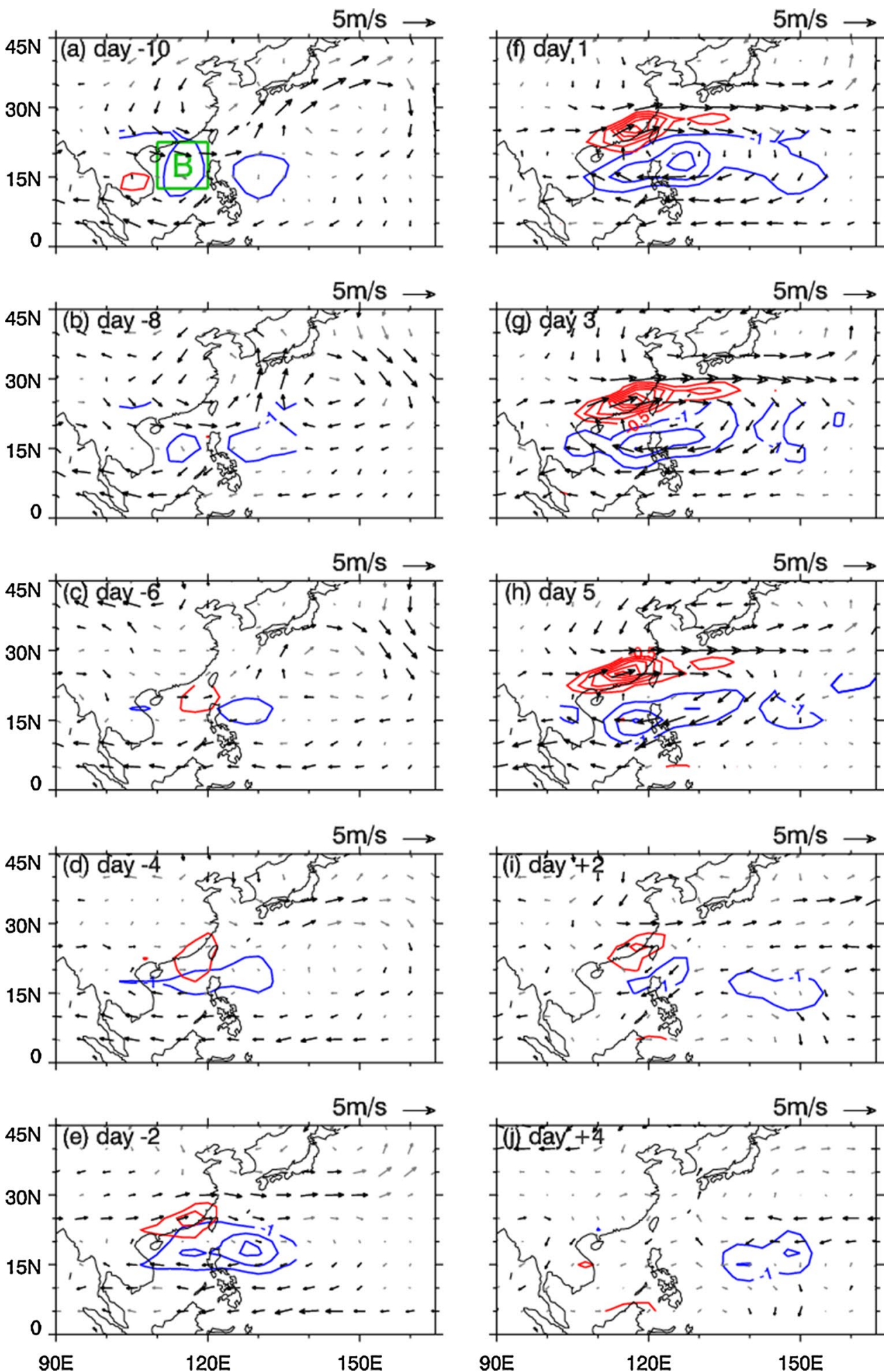

tongue there (black contours). Such accumulation, on one hand, satisfies the moisture supply for extreme precipitation; on the other hand, it enhances local instability. Actually, at this stage, a northward-tilted front is taking shape to the immediate north of the YRV (judged by equivalent potential temperature, figure not show). So the warm/moist air is elevated above the YRV along the front. Meanwhile, the upper-level northerlies associated with the SAH bring extra negative vorticities to the immediate south of the YRV (grey contours). Resultant upper-level convergences trigger strong descent (Holton 2013). Constituted by these anomalous flows, a saliently anomalous vertical circulation cell 
Fig. 9 As for Fig. 6, but for region-B at $500 \mathrm{hPa}$ (a)
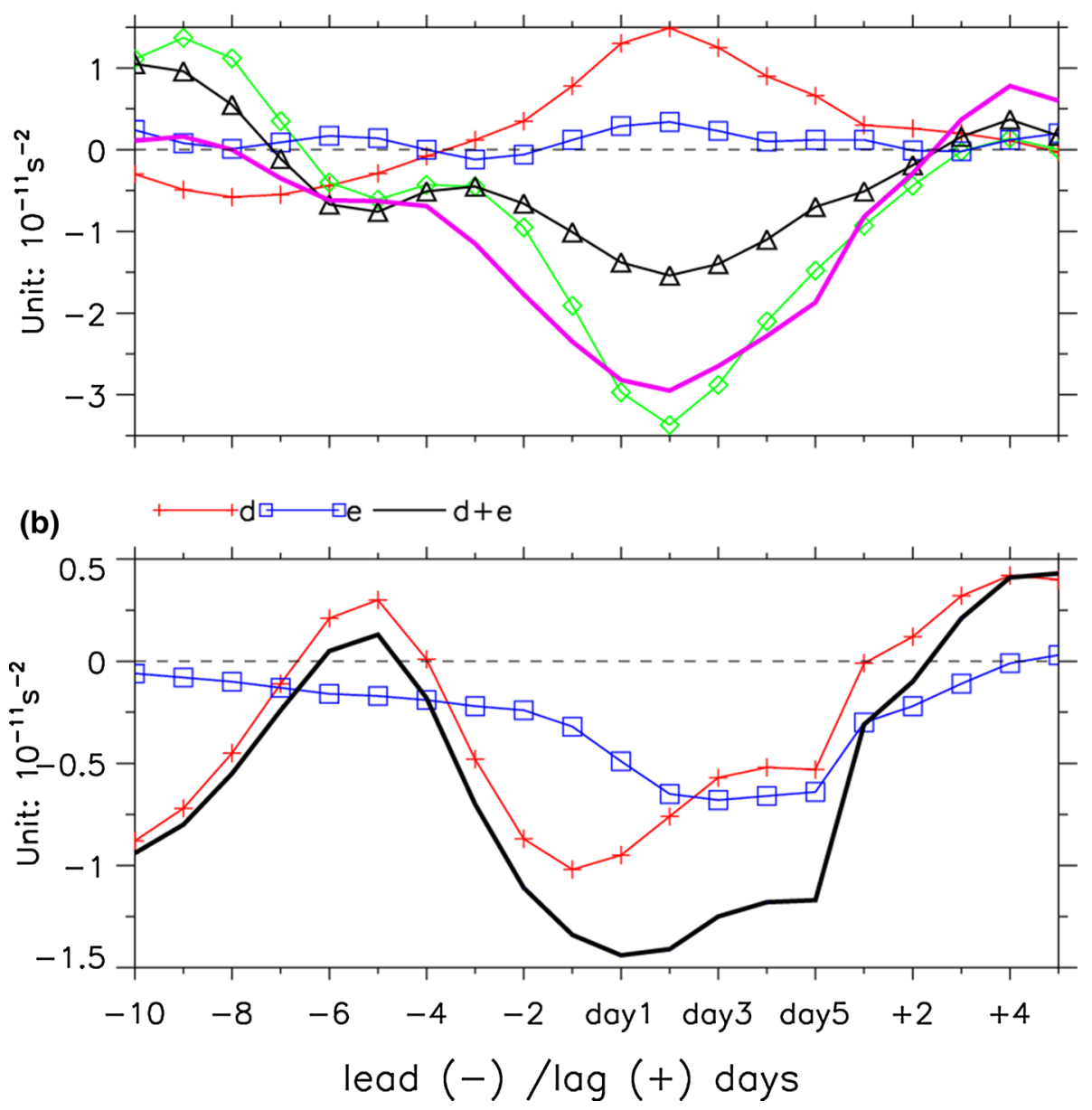

can be discerned to the south of the YRV. The strong anomalous descent to the south is conductive to amass air in the lower level. Such mass accumulation anchors the WPSH to the west of $120^{\circ} \mathrm{E}$ via forming a positive isallobaric region. The low-level westerlies to the north of the descent accordingly accelerate and further convert to southwesterlies via influences of the Coriolis force. These enhanced westerlies and southwesterlies in turn transport more abundant moisture toward the YRV, resulting in more latent heat release. This diabatic heating in the YRV greatly enhances the meridional temperature gradient in the mid-upper levels, enhancing the upper westerlies to the north (Figs. 5e, 10a). Thus, the YRV is located beneath the southern section of the jet entrance region, where tends to exist strong divergence. The anomalies of the WPSH and the SAH, as well as the favorable moist transport and upper-level divergence, form a positive feedback process. This positive feedback render the southern cell self-maintaining. The importance of diabatic heating in maintaining such southern cell has been confirmed in both specific case study and model simulations (Chen et al. 1998; Qian et al. 2004; Jin et al. 2013).
During PEPEs, apart from the existing southern vertical cell, another obvious circulation cell can also be detected to the north of the YRV. The low-level northerlies beneath the northern cell strongly converge with the southerlies of the southern cell. The ascent correspondingly strengthens substantially, further leading to release of more latent heating. More obvious moisture accumulation is restricted well above the YRV. The southern cell is better-developed as suggested by its stronger descent branch. As a consequence, the above positive feedback process maintains and strengthens. Also markedly enhanced is the low-level westerly and upper-level jet (purple contours). Manifestly, this self-maintaining positive feedback process is capable of persisting for several days (day 1 to day 5). Of particular note is that compared with the northern decent, the decent of the southern branch initiates earlier, disappears later, behaves more organized and stronger. Obviously, the negative vorticity advection caused by the eastward-extended SAH is the most determinant factor. Such difference clearly highlights the vital role of the eastward-extended SAH in determining the intensity and the duration of PEPEs. 
Fig. 10 Latitude-pressure cross $\left(115^{\circ} \mathrm{E}-125^{\circ} \mathrm{E}\right)$ of composite significant anomalies of diabatic heating rate (shadings, $\mathrm{K} \mathrm{day}^{-1}$ ), anomalies of U-wind (purple contours, $\mathrm{m} \mathrm{s}^{-1}$ ), anomalies of horizontal vorticity advection (grey contours, from $-1 \times 10^{-11} \mathrm{~s}^{-2}$ to $-3 \times 10^{-11} \mathrm{~s}^{-2}$ with interval of $-0.5 \times 10^{-11} \mathrm{~s}^{-2}$ ), specific humidity from 2 to $8 \mathrm{~g} / \mathrm{kg}$ with interval of $2 \mathrm{~g} / \mathrm{kg}$ (black contours), wind anomalies (vectors, $v$ component- $\mathrm{m} \mathrm{s}^{-1}$, $\omega$ component $-0.01 \mathrm{pa} \mathrm{s}^{-1}$ ).

The wind anomalies that are significant at the 0.05 level are highlighted by black vectors. Only the negative vorticity anomalies below $-1 \times 10^{-11}$ $\mathrm{s}^{-2}$, positive $\mathrm{U}$-wind anomalies above $5 \mathrm{~m} \mathrm{~s}^{-1}$, and positive specific above $2 \mathrm{~g} / \mathrm{kg}$ are shown. The number above each panel represents the same meaning of that in Fig. 2. The green dotdashed lines label the region of the Yangtze River Valley
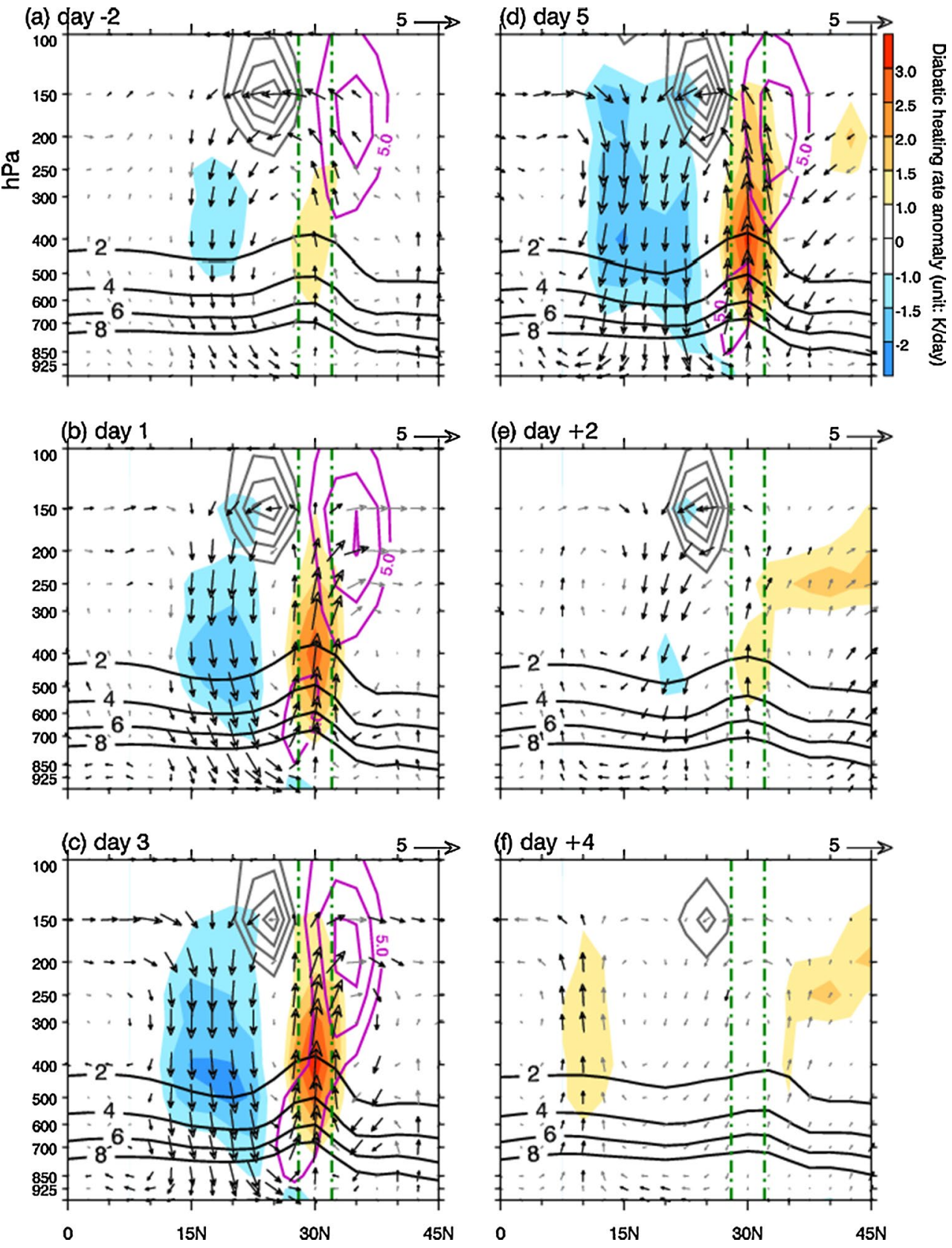

\subsection{Mechanisms for departure}

The question of how is the positive feedback process terminated may be raised naturally. Obviously, after PEPEs, an anomalous heating appears to the north of the YRV (Fig. 10e). Correspondingly, the previous strong ascent in the YRV is largely suppressed and eventually converts to descent (Fig. 10f), and conspicuous divergence appears at the lower troposphere around the YRV (Fig. 11). Release of latent heating in the YRV is therefore dampened as indicated by positive OLR anomaly in Fig. 11. Accordingly, the southern vertical cell, which is the key factor maintaining extreme precipitation, rapidly weakens to dissipation.
Actually, during PEPEs, the coastal region with strong descent atop experienced increasing incident solar radiation and decreasing upward latent heat flux from surface, both of which contribute to positive sea surface temperature anomalies (SSTAs) (see Ren et al. 2013). The warmer SSTs and more incident solar radiation accelerate the evaporation from local sea surface. Such warmer and wetter environment gradually establishes a convective instability condition. Similar accumulation of local moisture can also be apparently observed in the immediate north of the YRV, where anomalous descent prevails during PEPEs as well. The warmer SSTs and resultant convective instability condition are favorable to a swift transition of low-level 


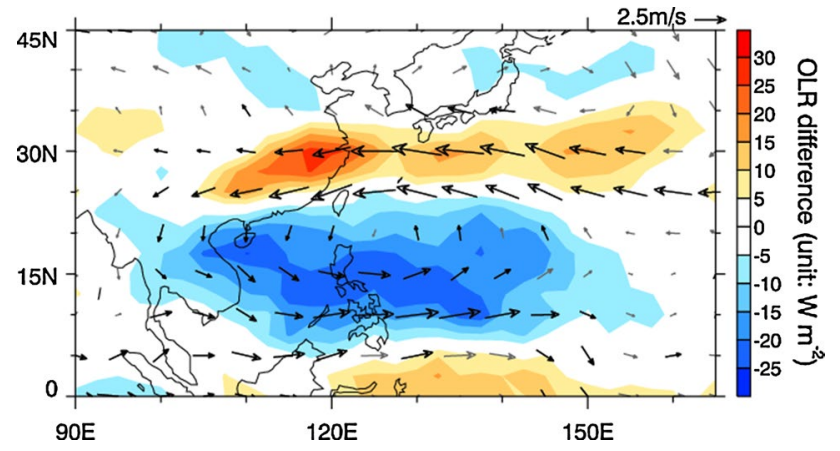

Fig. 11 Difference fields between the periods after PEPEs (day +1 to day +5 ) and the periods during PEPEs (day 1-5), including $500 \mathrm{hPa}$ wind (vectors, $\mathrm{m} \mathrm{s}^{-1}$ ) and OLR (shadings, $\mathrm{W} \mathrm{m}^{-1}$ ). Differences in wind that are significant at least at the 0.05 level is highlighted by black vectors. Only the OLR differences significant at the 0.05 level at least are shown

circulation from anticyclonic to cyclonic anomalies over the coastal region (Gill 1980; Ren et al. 2013), as displayed in Fig. 11. The development of convective activity to the north of the YRV and suppression of the latent heating in the YRV can also be apparently identified in Fig. 11. The eastward retreat of the WPSH is clearly indicated by the cyclonic circulations. Consequently, the development of positive $\mathrm{Q}$ anomalies caused by local land-air interaction in the north and local sea-air interaction in the south combine to terminate the long-lasting positive feedback process.

After PEPEs, the vorticity centers spatially lead the wave-like pattern of $\mathrm{Q}$ again. The re-appearance of this vorticity-Q relationship signals next round of northwest propagation of $\mathrm{Q}$, which is soon confirmed by Fig. $2 \mathrm{j}$. This phenomenon is also consistent with the appearances of heating both to the north and south of the YRV revealed in Fig. 11. This restarted northwest propagation of $\mathrm{Q}$ alters previous favorable diabatic heating/cooling configuration and then dampens the negative vorticity genesis. Correspondingly, both the WPSH and the SAH retreat to their normal positions.

\section{Conclusions and discussions}

The western Pacific subtropical high (WPSH) and the South Asia high (SAH) are two dominant systems responsible for persistent extreme precipitation events (PEPEs) in the Yangtze River Valley (YRV). Before and during PEPEs, conspicuous zonal approach between the WPSH and the SAH can be observed, in spite of various configured anomalous circulations at mid-high latitudes. Based on diagnosis of vorticity genesis and dissipation, a northwestward migrating wave-like pattern of anomalous apparent heat source $(\mathrm{Q})$ is deemed largely responsible for such concurrent anomalous behaviors of the WPSH and the SAH. Mechanisms for the approach, maintenance, and departure of these two key systems are investigated in detail. Main conclusions are summarized as follows:

1. Prior to PEPEs, the wave-like pattern of anomalous $\mathrm{Q}$ stretches from the equatorial central Pacific to centraleastern China. During the early period (up to 10 days prior to PEPEs), this wave-like pattern is mainly characterized by westward migration, followed by gradual northward progression. Accordingly, components of this northwest propagating wave-like pattern result in a sharper vertical decrease and an enhanced meridional gradient of Q, both of which force anomalously negative vorticities to the east of the normal SAH. The SAH therefore extends eastward (day -5). An anomalously negative Q exists around the South China Sea since day -10 , and it is replenished by subsequent westward-extended negative $\mathrm{Q}$ anomalies. These negative $\mathrm{Q}$ anomalies act to reduce the increase of $\mathrm{Q}$ with height in the lower-mid troposphere, triggering anomalously negative vorticities to the west of the WPSH. Accordingly, the WPSH progresses westward gradually. During the later period (after day -3 ), the changes in meridional gradient of $\mathrm{Q}$ at $500 \mathrm{hPa}$ account for the northward expansion of the WPSH.

2. During PEPEs, the wave-like pattern of anomalous $\mathrm{Q}$ with greater intensity is anchored over East Asia. A positive feedback mechanism may explain the maintenance of PEPEs. A thermal-inducing anomalous vertical cell in the immediate south of the YRV is constituted by strong ascent in the YRV, upper-level northerly to the east periphery of the $\mathrm{SAH}$, strong descent caused by negative vorticity advections, and low-level southwesterlies along the north flank of the WPSH. As diabatic heating enhances in the YRV, another vertical cell can also be identified in the immediate north of the YRV, with ascent in the YRV and descent in the north. This northern cell tends to be neglected in previous studies. The stronger convergence between southwesterlies from the southern cell and northeasterlies from the northern cell in the lower-level strengthens the ascent within the YRV, releasing more latent heat. These processes seem self-maintaining.

3. After PEPEs, ascent and resultant diabatic heating appear to the immediate north of the YRV, where strong descent prevails during PEPEs. The previous descent contributes to increasing incident solar radiation and decreasing upward latent heat flux, both of which lead to low-level heat/moisture accumulation and resultant unstable conditions for convection development. A reverse vertical cell, with ascent in the north and descent in the YRV, replaces the previous north- 
Table 2 Lead-lag correlation between circulation indices and precipitation during day -10 to day +10

\begin{tabular}{|c|c|c|c|c|c|c|c|c|c|c|c|c|c|}
\hline & \multicolumn{6}{|c|}{ Circulation leads precipitation (day) } & \multirow[b]{2}{*}{0} & \multicolumn{6}{|c|}{ Precipitation leads circulation (day) } \\
\hline & -6 & -5 & -4 & -3 & -2 & -1 & & 1 & 2 & 3 & 4 & 5 & 6 \\
\hline WPSH-Precip. & 0.08 & 0.30 & 0.52 & 0.72 & 0.86 & 0.91 & 0.85 & 0.65 & 0.38 & 0.06 & -0.24 & -0.50 & -0.69 \\
\hline SAH-Precip. & -0.06 & 0.16 & 0.38 & 0.58 & 0.72 & 0.77 & 0.70 & 0.56 & 0.35 & 0.08 & -0.22 & -0.46 & -0.57 \\
\hline
\end{tabular}

The negative/positive values listed in the second row denote that the circulation indices lead/lag precipitation indices. Value 0 denotes simultaneous correlation. The correlation coefficients that are significant at the 0.05 level are displayed in bold ern cell. Accordingly, release of latent heating above the YRV vanishes rapidly, leading to a termination of the above positive feedback processes. Also, another descent-prevailing region during PEPEs, i.e. South China Sea, witnesses warmer SSTs and accumulation of moisture after PEPEs, both of which boost a swift transition of low-level circulation from anticyclone to cyclone. Thus, anomalously abundant moisture transport failed to be sustained, and atmospheric instability in the YRV reduced. So such local sea-air interaction also terminates the positive feedback process. Thus, the $\mathrm{SAH}$ and the WPSH depart from each other, retreating to their climatologically normal positions.

Though it has been showed that the zonal approach precedes PEPEs onset about 1 week, one may still suspect that the anomalies of the WPSH and SAH may be determined by PEPEs, rather than act as the precursors. To illuminate this issue, three indices of 25 days (preceding 10 days, persisting 5 days, and following 10 days), for the WPSH, $\mathrm{SAH}$, and precipitation are constructed respectively. The length of 25-day contains necessary information of evolving, maintaining, and decaying processes, and eliminates noises beyond the above processes. The lead-lag correlation results are displayed in Table 2. Manifestly, the anomalies of WPSH and the SAH lead the precipitation intensification a few days, while the role of precipitation on circulations mainly reflects sort of simultaneous interactions. The lag correlation reveals that a few days after the extreme precipitation, both of the WPSH and the SAH weaken, actually meaning their retreats. This is consistent with the results displayed in Fig. 2i-j. The correlation between the WPSH and the SAH indicates that they move almost simultaneously, with the WPSH developing slightly early (values not shown). So the zonal approach between the WPSH and the SAH can be confirmed as precursors, and they can providing some useful clues for PEPEs forecasting with lead time about 1 week. Additionally, the larger correlation coefficients of WPSH-precipitation imply that the westwardextended WPSH may be a more reliable precursor.

One may feel confused why significant negative diabatic cooling from the South China Sea to northern Philippines failed to force obvious vorticity anomalies at $200 \mathrm{hPa}$ locally (Fig. 5, blue contours). Actually, a large verticallyintegrated Q anomaly can't ensure a heavily modified structure of $Q$ through different levels, i.e. a significantly sharper or a weaker decrease/increase of $\mathrm{Q}$ with height. In particular, during early stages, to the northwest of the Philippines where negative $\mathrm{Q}$ anomaly prevails, vertical profile of $\mathrm{Q}$ seems to parallel to its climatology at the upper levels (Figure not shown). So the local decreases of $\mathrm{Q}$ with height are of similar magnitude between selected events and climatological situation. Accordingly, the absolute value of local $\frac{\partial Q}{\partial z}$ anomaly around $200 \mathrm{hPa}$ is only 0.09 , far smaller than that caused by the anomalous heating to the north (about 0.45 ) as shown in Fig. 7a. The trivial forced vorticity tendency is about $0.15-0.7 \mathrm{~s}^{-2}$ locally, and contours of such negligible values are omitted. Also, for the latter period, though the anomalous cooling obviously modifies the local vertical profile, major changes occurred in the mid-lower levels. While for the upper levels around $200 \mathrm{hPa}$, the profile nearly parallels to its climatological situation. So the local anomaly of $\frac{\partial Q}{\partial z}$ is still very weak (about 0.13 ). Similarly, during day 1 to day 5, in spite of positive verticallyintegrated Q anomaly around the YRV, it fails to substantially alter the vertical distribution of Q around $200 \mathrm{hPa}$. The anomaly of local $\frac{\partial Q}{\partial z}$ is only 0.11 , which is ineffective in inducing anomalous vorticity at the upper levels.

Additional isolated events (1-day) are used to make comparisons with PEPEs (Figures not shown). An isolated event is defined as extreme precipitation only in 1 day, whose preceding 3 days and subsequent 3 days are dry days with daily precipitation less than $1 \mathrm{~mm}$ day $^{-1}$. The results indicate that despite potentially higher extremity of the isolate events, they are not necessarily accompanied by simultaneous westward-extended WPSH and eastward-extended SAH. Also, no wave-like pattern of anomalous Q is identified prior to isolated events. The positive feedback process and long-lasting vertical cells fail to be recognized either. These differences clearly illustrate local convective nature of isolated events, and further highlight the importance of systematic anomalies in dominant circulation components in forming quasi-stationary front and resultant PEPEs. In spite of the same or even stronger release of latent heating during isolated events, the absence of zonal approach verifies the fact that the concurrent anomalies between the 
WPSH and the SAH is the motivating factor, rather than a passive response to local heating.

Currently, the anomaly of every item in Eq. (2) is discussed as a whole. The follow-up study can partition the anomaly into synoptic components, intraseasonal parts and their interacted agents. Thus, relative contributions from anomalies of different timescales can be effectively estimated. Given relatively accurate delineation of these processes, the prediction on occurrence, duration, and intensity of PEPEs in the YRV with lead time of 1-2 weeks would be anticipated. Related forecasted results are of great value in disaster prevention and mitigation.

Acknowledgments This study was supported by the National Key Basic Research Program of China (Grant No. 2012CB417205).

Open Access This article is distributed under the terms of the Creative Commons Attribution 4.0 International License (http://creativecommons.org/licenses/by/4.0/), which permits unrestricted use, distribution, and reproduction in any medium, provided you give appropriate credit to the original author(s) and the source, provide a link to the Creative Commons license, and indicate if changes were made.

\section{References}

Archambault HM, Bosart LF, Keyser D, Aiyyer AR (2008) Influence of large-scale flow regimes on cool-season precipitation in the northeastern United States. Mon Weather Rev 138:3454-3473

Archambault HM, Keyser D, Bosart LF (2010) Relationships between large-scale regime transitions and major cool-season precipitation events in the northeastern United States. Mon Weather Rev 136:2945-2963

Cao X, Ren XJ, Yang XQ, Fang JB (2012) The quasi-biweekly oscillation characteristics of persistent severe rain and its general circulation anomaly over southeast China from May to August. Acta Meteoral Sin 70(4):766-778 (in Chinese)

Chen Y, Zhai P (2013) Persistent extreme precipitation events in China during 1951-2010. Clim Res 57:143-155

Chen Y, Zhai P (2014a) Precursor circulation features for persistent extreme precipitation in central-Eastern China. Weather Forecast 29:226-240

Chen Y, Zhai P (2014b) Two types of typical circulation pattern for persistent extreme precipitation in Central-Eastern China. Q J R Meteorol Soc 140:1467-1478

Chen Y, Zhai P (2015) Synoptic-scale precursors of the East/Asia Pacific teleconnection pattern responsible for persistent extreme precipitation in the Yangtze River Valley. Q J R Meteorol Soc 141:1389-1403

Chen C, Tao W-K, Lin P-L, Lai GS, Tseng S-F, Wang T-CC (1998) The intensification of the low-level jet during the development of mesoscale convective systems on a mei-yu front. Mon Weather Rev 126:349-371

Chen GT-J, Wang CC, Wang AH (2007) A case study of subtropical frontgenesis during a blocking event. Mon Weather Rev 135:2588-2609

Dee DP et al (2011) The ERA-Interim reanalysis: configuration and performance of the data assimilation system. Q J R Meteorol Soc $137: 553-597$
Ding Y (1992) Summer monsoon rainfalls in China. J Meteorol Soc Jpn 70:373-396

Ding Y, Chan JC (2005) The East Asian summer monsoon: an overview. Meteorol Atmos Phys 89:117-142

Dole R, Hoerling M, Perlwitz J, Eischeid J, Pegion P, Zhang T, Quan XW, Xu T, Murray D (2011) Was there a basis for anticipating the 2010 Russian heat wave? Geophys Res Lett 38:L06702. doi: 10.1029/2010GL046582

Ertel H (1942) Ein neuer hydrodynamischer Wirbelsatz. Meteorol Z 59:277-281

Fukutomi Y, Yasunari T (1999) 10-25-day intraseasonal variations of convection and circulation over East Asia and western North Pacific during early summer. J Meteorol Soc Jpn 77:753-769

Galarneau TJ Jr, Hamill TM, Dole RM, Perlwitz J (2012) A multiscale analysis of the extreme weather events over western Russia and Northern Pakistan during July 2010. Mon Weather Rev 140:1639-1664

Gill AE (1980) Some simple solutions for heat-induced tropical circulation. Q J R Meteorol Soc 106:447-462

Grotjahn R, Faure G (2008) Composite predictor maps of extraordinary weather events in the Sacramento, California, Region. Weather Forecast 23:313-335

Grumm RH, Hart RH (2001) Standardized anomalies applied to significant cold season weather events: preliminary findings. Weather Forecast 16:736-754

Hart RE, Grumm RH (2001) Using normalized climatological anomalies to rank synoptic-scale events objectively. Mon Weather Rev 129:2426-2442

Hong CC, Hsu HH, Lin NH, Chiu H (2011) Roles of European blocking and tropical-extratropical interaction in the 2010 Pakistan flooding. Geophys Res Lett 38:L13806. doi:10.1029/201 $1 \mathrm{GL} 047583$

Hong W, Ren XJ, Yang XQ (2015) The influences of the low-frequency diabatic heating on the low-frequency circulation during the persistent severe rainfall period over South China. Acta Meteorol Sin 73(2):276-290 (in Chinese)

Hoskins BJ, McIntyre M, Robertson AW (1985) On the use and significance of isentropic potential vorticity maps. Q J R Meteorol Soc 111:877-946

Holton JR (2004) An introduction to dynamics meteorology. 4th edn. Academic press, Burlington

Hsu HH, Weng CH (2001) Northwestward propagation of the intraseasonal oscillation in the western North Pacific during the boreal summer: structure and mechanism. J Clim 14:3834-3850

Jin Q, Yang X-Q, Sun X-G, Fang J-B (2013) East Asian summer monsoon circulation structure controlled by feedback of condensational heating. Clim Dyn 41:1885-1897

Junker NW, Grumm RH, Hart R, Bosart LF, Bell KM, Pereira FJ (2008) Use of normalized anomaly fields to anticipate extreme rainfall in the mountains of northern California. Weather Forecasting 23:336-356

Kalnay E, Kanamitsu M, Kistler R, Collins W, Deaven D, Gandin L, Iredell M, Saha S, White G, Woollen J (1996) The NCEP/NCAR 40-year reanalysis project. Bull Am Meteorol Soc 77:437-471

Kanamitsu M, Ebisuzaki W, Woollen J, Yang S-K, Hnilo J, Fiorino M, Potter G (2002) NCEP-DOE AMIP-II Reanalysis (R-2). Bull Am Meteorol Soc 83:1631-1643

Kemball-Cook S, Wang B (2001) Equatorial waves and air-sea interaction in the boreal summer intraseasonal oscillation. J Clim 14:2923-2942

Kikuchi K, Wang B (2009) Global perspective of the quasi-biweekly oscialltion. J Clim 22:1340-1359

Lau WK, Kim K-M (2012) The 2010 Pakistan flood and Russian heat wave: teleconnection of hydrometeorological extremes. J Hydrometeorol 13:392-403 
Lau K-M, Weng H (2002) Recurrent teleconnection patterns linking summertime precipitation variability over East Asia and North America. J Meteorol Soc Jpn 80:1309-1324

Liebmann B, Smith CA (1996) Description of a complete (interpolated) outgoing longwave radiation dataset. Bull Am Meteorol Soc 77:1275-1277

Liu Y, Wu G, Liu H, Liu P (1999) The effect of spatially nonuniform heating on the formation and variation of subtropical high. Part III: condensation heating and South Asia high and Western Pacific subtropical high. Acta Meteorologica Sinica 57:525-538

Liu Y, Wu G, Liu H, Liu P (2001) Condensation heating of the Asian summer monsoon and the subtropical anticyclone in the Eastern Hemisphere. Clim Dyn 17:327-338

Liu Y, Guoxiong Wu M-M, Rongcai Ren M-M (2004) Relationship between the subtropical anticyclone and diabatic heating. J Clim 17:682-698

Liu B, Wu G, Mao J, He J (2013) Genesis of the South Asian High and Its Impact on the Asian Summer Monsoon Onset. J Clim 26:2976-2991

Lu R, Lin ZD (2009) Role of subtropical precipitation anomalies in maintaining the summertime meridional teleconnection over the western North Pacific and East Asia. J Clim 22:2058-2072

Mao J, Wu G (2006) Intraseasonal variations of the Yangtze rainfall and its related atmospheric circulation features during the 1991 summer. Clim Dyn 27:815-830

Mao J, Sun Z, Wu G (2010) 20-50-day oscillation of summer Yangtze rainfall in response to intraseasonal variations in the subtropical high over the western North Pacific and South China Sea. Clim Dyn 34:747-761

McTaggart-Cowan R, Bosart LF, Gyakum JR, Atallah EH (2007) Hurricane Katrina (2005). Part II: evolution and hemispheric impacts of a diabatically generated warm pool. Mon Weather Rev 135:3927-3949

Müller M, Kašpar M, Řezáčová D, Sokol Z (2009) Extremeness of meteorological variables as an indicator of extreme precipitation events. Atmos Res 92:308-317

Ninomiya K, Shibagaki Y (2007) Multi-scale features of the MeiyuBaiu front and associated precipitation systems. J Meteorol Soc Jpn 85:103-122

Pyper BJ, Peterman RM (1998) Comparison of methods to account for autocorrelation in correlation analyses of fish data. Can J Fish Aquat Sci 55:2127-2140

Qian J-H, Tao W-K, Lau K-M (2004) Mechanisms for torrential rain associated with the mei-yu development during SCSMEX 1998. Mon Weather Rev 132:3-27

Ren R, Liu Y, Wu G (2007) Impacts of South Asia High on the shortterm variation of the subtropical anticyclone over western Pacific in July 1998. Acta Meteorol Sin 2(65):183-197

Ren XJ, Yang XQ, Sun X (2013) Zonal oscillation of Western Pacific subtropical high and subseasonal SST Variations during Yangtze persistent heavy rainfall events. J Clim 26:8929-8946

Ren X, Yang DJ, Yang XQ (2015) Characteristics and mechanisms of the subseasonal eastward extension of the South Asian High. J Clim. doi:10.1175/JCLI-D-14-00682.1

Root B, Knight P, Young G, Greybush S, Grumm R, Holmes R, Ross J (2007) A fingerprinting technique for major weather events. J Appl Meteorol Clim 46:1053-1066
Samel AN (2003) Understanding relationships between the 1998 Yangltlze River flood and Northeast Eurasian bloc'ng. Clim Res 23:149-158

Shapiro MA, Thorpe AJ (2004) THORPEX international science plan. WMO/TD 1246

Simmonds I, Bi D, Hope P (1999) Atmospheric water vapor flux and its association with rainfall over China in summer. J Clim 12:1353-1367

Sisson PA, Gyakum JR (2004) Synoptic-scale precursors to significant cold-season precipitation events in Burlington, Vermont. Weather Forecast 19:841-854

Wang B, Xie X (1996) Low-frequency equatorial waves in vertically sheared zonal flow. Part I: stable waves. J Atmos Sci 53:449-467

Wang W-C, Gong W, Wei H (2000) A regional model simulation of the 1991 severe precipitation event over the Yangtze-Huai River Valley. Part I: precipitation and circulation statistics. J Clim 13:74-92

Webster P, Toma V, Kim HM (2011) Were the 2010 Pakistan floods predictable? Geophys Res Lett 38:L04806. doi:10.1029/201 0GL046346

Wei W, Zhang R, Wen M, Kim BJ, Nam JC (2015) Interannual variation of the south asian high and its relation with indian and east asian summer monsoon rainfall. J Clim 28:2623-2634

Welch BL (1947) The generalization of student's problem when several different population variances are involved. Biometrika 34:28-35

Worton BJ (1989) Kernel methods for estimating the utilization distribution in home-range studies. Ecology 70:164-168

Wu G-X, Liu H-Z (1998) Vertical vorticity development owing to down-sliding at slantwise isentropic surface. Dyn Atmos Oceans 27:715-743

Wu G-X, Liu Y (2003) Summertime quadruplet heating pattern in the subtropics and associated atmospheric circulation. Geophys Res Lett 30:1201. doi:10.1029/2002GL016209

Wu G-X, Liu H, Liu P (1999) The effect of spatially nonuniform heating on the formation and variation of subtropical high. Part I: scale analysis (in Chinese). Acta Meteorol Sin 57:257-263

Xie X, Wang B (1996) Low-frequency equatorial waves in vertically sheared zonal flow. Part II: unstable waves. J Atmos Sci 53:3589-3605

Yanai M, Esbensen S, Chu J-H (1973) Determination of bulk properties of tropical cloud clusters from large-scale heat and moisture budgets. J Atmos Sci 30:611-627

Yang J, Wang B, Wang B, Bao Q (2010) Biweekly and 21-30-day variations of the subtropical summer monsoon rainfall over the lower reach of the Yangtze River Basin. J Clim 23:1146-1159

Zhang B,Zhou XJ, Chen LX, Zhu YF, Zhao B (2010) An East Asian land-sea atmospheric heat source difference index and its relation to general circulation and summer rainfall over China. Sci China Ser D: Earth Sci 1:1-13

Zhang X, Alexander L, Hegerl GC, Jones P, Tank AK, Peterson TC, Trewin B, Zwiers FW (2011) Indices for monitoring changes in extremes based on daily temperature and precipitation data. Wiley Interdiscip Rev Clim Change 2:851-870

Zhou TJ, Yu RC (2005) Atmospheric water vapor transport associated with typical anomalous summer rainfall patterns in China. J Geophys Res Atmos 110:D08104. doi:10.1029/2004JD005413 